\title{
Physiological Characterization of the Chitin Synthase A Gene Responsible for Biosynthesis of Cuticle Chitin in Culex Pipiens Pallens (Diptera: Culicidae)
}

\author{
Xiaoshan Yang \\ Nanjing Medical University \\ Yang Xu \\ Nanjing Medical University \\ Qi Yin \\ Nanjing Medical University \\ Hongbo Zhang \\ Nanjing Medical University \\ Haitao Yin \\ Nanjing Medical University \\ Yan Sun \\ Nanjing Medical University \\ Lei Ma \\ Nanjing Medical University \\ Dan Zhou \\ Nanjing Medical University \\ Bo Shen ( $\nabla$ shenbo@njmu.edu.cn ) \\ Nanjing Medical University
}

\section{Research}

Keywords: Chitin, Chitin synthase, molting, mosquito, insect

Posted Date: January 6th, 2021

DOI: https://doi.org/10.21203/rs.3.rs-139574/v1

License: () (1) This work is licensed under a Creative Commons Attribution 4.0 International License. Read Full License 
Version of Record: A version of this preprint was published at Parasites \& Vectors on May 1st, 2021. See the published version at https://doi.org/10.1186/s13071-021-04741-2. 


\section{Abstract}

Background: The pathogens transmitted by mosquitoes (Culex pipiens pallens) to humans and animals cause several emerging and resurgent infectious diseases. Increasing insecticide resistance requires rational action to control the target vector population. Chitin is indispensable for insect growth and development and absent from vertebrates and higher plants. Chitin synthase A (CHSA) represents a crucial enzyme in chitin synthesis; therefore, identifying and characterizing how CHSA determines the chitin content might help with novel vector control strategies.

Results: The injection of small interfering RNA targeting CHSA (siCHSA) to knock down CHSA transcripts of in larval, pupal, and adult stages, showed different lethal phenotypes. In the larval and pupal stages, CHSA knockdown prevented larval molting, pupation, and adult eclosion, and affected the production of chitin and chitin degradation, which resulted in an ecdysis defect phenotype of mosquitoes. In the adult stage, it also affected the laminar organization of mesoderm and the formation of pseudo orthogonally large fibers of the endoderm.

Conclusion: The present study provides a systematic and comprehensive description of the effects of CHSA on morphogenesis and metamorphosis. The results showed that CHSA not only affects chitin synthesis during molting, but also might be involved in chitin degradation. Our result further showed that CHSA is important for the structural integrity of the adult mosquito cuticle.

\section{Background}

Mosquitoes are the vectors for transmission of many infectious diseases, causing hundreds of thousands of deaths every year [1-5]. Currently, chemical insecticides are the main agents used to control insect vectors and reduce disease transmission. However, the widespread use of chemical control has led to the development of insect resistance, the resurgence of target pests, food and environment pollution, and the destruction of non-target insects [6-8]. The environmental and health impacts of the toxicity of conventional insecticides have become increasingly unacceptable [9]. Therefore, there is an urgent need to develop novel, safer bioinsecticides with low toxicity [10]. The normal growth and development of insect is inseparable from the process of molting [11]. Many researchers investigated growth metabolic regulation and metabolism strategies in insects to identify novel targets for insect control [12-17].

The process of insect molting involves the biosynthesis, transformation, and modification of chitin [18]. Chitin, a linear polysaccharide of the amino sugar $\mathrm{N}$-acetyl glucosamine, is the main component of insects' extracellular barrier, such as the cuticle and the peritrophic matrix (PM). Chitin is also an important component in the tracheal system, reproductive ducts, and the ducts of various dermal glands in the internal structures of many insects [6,9]. Chitin plays an important role in supporting muscle attachment for movement, preventing chemical and physical damage, and preventing infectious diseases, representing the first line of defense in challenging environments $[19,20]$. 
Chitin biosynthesis plays an irreplaceable role in the growth of insects. Chitin biosynthesis requires modification and physiological regulation at developmental stages. Chitin is completely absent from vertebrates and higher plants[21,22], and thus has generated interest as a potential target for ecologically friendly insecticides; therefore, an understanding of chitin biosynthetic pathways could provide additional strategies for pest control. Chitin synthesis inhibitors (CSI) can prevent insects from molting by interfering with chitin biosynthesis [8]. Among them, the Benzylphenolurea (BPU) insecticides have shown great potential to inhibit chitin biosynthesis; however, the non-targeting effects of BPUs can adversely affect beneficial species, such as bees, making them a controversial group of insecticides [7]. Therefore, it is necessary to study chitin synthase to find new and effective target sites to combat insect pests.

The chitin biosynthesis pathway involves eight key regulatory enzymes. The last step is executed by the chitin synthases (CHSs, UDP-N-acetyl-D- glucosamine: chitin 4-beta-N-acetylglucosaminyltransferase), which form a large group of plasma membrane proteins belonging to family 2 of the glycosyltransferases [23]. Insects commonly possess two chitin synthase genes: class A CHSs (CHSA) are primarily involved in chitin synthesis for the exoskeleton cuticle [24-28]; while class B CHSs (CHSB) play a major role in the synthesis of chitin in the intestinal PM $[9,29]$. Currently available data of biochemically characterized insect CHSs show that insect CHSA is associated with insect molting [30, 31], and is a crucial enzyme that balances growth and development. RNA interference (RNAi) to silence CHSA in Manduca sexta [32] and Spodopetera exigua resulted in disruption of the cuticular exoskeleton and tracheal ectodermis [33]. In Triboliumcastaneum and Locusta migratoria manilensis, CHSA is required for larval-larval processes, and for larval-pupal and pupal-adult processes [34]. In Tribolium castaneum, CHSA plays a prominent role in embryo development and oviposition [31]. In Anopheles gambiae, CHSA was detected in newly formed compound eyes [26]. However, those studies were performed in different developmental stages of different species, and the mechanism by which CHSA affects the molting process in mosquitoes remains unclear. Studying CHSA function in mosquitoes is crucial to acquire a full understanding of the regulatory processes of mosquito growth and reproduction, and might lead to the utilization of the CHSA gene in new approaches to insect control.

Culex pipiens pallens (C. pipiens pallens) is a common house mosquito and is a vector of West Nile virus (WNV), epidemic encephalitis, Wucheraria bancrofti, and Brugia malavi [35]. In the present study, we aimed to identify and characterize the CHSA gene from C. pipiens pallens ( $C p C H S A)$. We used RNAi to identify whether $C P C H S A$ is essential for growth and development at different development stages and in different tissues of $C$. pipiens pallens. The results indicated that $C p C H S A$ affects chitin synthesis and degradation, which is necessary for molting and ecdysis processes. CpCHSA is also important for cuticle formation in adult stages, playing critical roles in endocuticle development.

\section{Materials And Methods Mosquito Rearing}


The $C$. pipiens pallens were reared at $28 \pm 1{ }^{\circ} \mathrm{C}$ and $70-80 \%$ relative humidity with a $12 \mathrm{~h}$ light and $12 \mathrm{~h}$ dark photoperiod. The larvae were fed with rat chow. Adult mosquitoes were maintained on $7 \%$ sucrose solution. The female mosquitoes were fed fresh mouse blood to induce egg laying. Mosquitoes were not treated with insecticides or other chemicals.

\section{CpCHSA cDNA cloning}

The RNAiso Plus reagent (Takara, Tokyo, Japan) was used to isolate RNA. The full-length sequence of CpCHSA cDNA was determined from seven overlapping PCR fragments (Additional file 1: Table S1). The 5 '- and 3'- end fragments were obtained using rapid amplification of cDNA ends (RACE) using a SMARTer RACE 5'/3' Kit (Takara). PCR amplification products were analyzed using agarose gels and then purified (TIANGEN, Beijing, China). Purified DNA was ligated into vector pClone007 (TSINGKE, Nanjing, China) and sequenced. The obtained full-length cDNA of $\mathrm{CpCHSA}$ was submitted to the NCBI and received the accession number $\mathrm{MH} 013352$.

\section{Analysis of gene expression patterns}

Total RNA was isolated from the larval stage ( $1 \mathrm{st}, 2 \mathrm{nd}, 3^{\text {rd }}$, and 4 th), pupal stage ( 0 and $24 \mathrm{~h}$ ) and adult stage (1-3 posteclosion (PE) and 1-3 post-blood meal (PBM)) to investigate the $C$. pipiens pallens developmental expression profile. The head, foregut, midgut, hindgut, Malpighian tubules, and carcass were dissected from 4th larvae or 3-d old adult mosquitoes for tissue-specific expression analysis. Total RNA was isolated from the whole bodies of five mosquitoes and the tissues of ten mosquitos for biological replicates. First stand cDNA was synthesized using PrimeScript RT Master Mix (Takara). A LightCycler® 96 Instrument was used for quantitative real-time PCR (qPCR) analysis (Roche, Basel, Switzerland) with the BrightGreen ${ }^{*} \mathrm{qPCR}$ MasterMix-No Dye (Applied Biological Materials, Vancouver, Canada). The specific primers are shown in Additional file 2: Table S2. The qPCR reaction volume $(10 \mu \mathrm{L})$ contained the Power SYBR Green PCR Master Mix, specific primer sequences, and diluted CDNA (1 $\mathrm{mg} / \mathrm{mL}$ ). The relative expression levels were normalized to the internal control ACTB (encoding $\beta$-actin) using the $2^{-\triangle \Delta C t}$ method [36]. All experiments were performed with three biological replicates.

\section{Microinjection}

RNAi was used to knockdown the expression of $C p C H S A$. The small interfering RNA sequences used to silence the CpCHSA gene (siCHSA) and negative control (NC) are shown in Additional file 3: Table S3, both of which were designed and manufactured by Gene Pharma (Shanghai, China). siCHSA or NC ( 0.30 $\mu \mathrm{g}$ ) was injected into the 3rd larvae abdomen and the adult female mosquitoe thorax. In the pupal stage, they were injected into the dorsal cuticle between the thorax and the abdomen. Both the wild-type (WT) group and NC group served as controls. Total RNA was isolated from whole mosquitoes $(n \geq 5)$, and CPCHSA transcript levels were analyzed after RNAi using qPCR. 


\section{Immunofluorescence staining}

The chitin content of the abdominal integuments was quantified after siCHSA or NC injection using chitin staining. Pupae $(0-1 \mathrm{~h})$ were selected to be injected with siRNA, and at $24 \mathrm{~h}$ after injection, the pupal abdomen was immediately dissected. Slides of paraffin-embedded tissue were deparaffinized in xylene and rehydrated using an ethanol gradient. Fluorescent Brightener 28 (Sigma-Aldrich, Hamburg, Germany) was used to stain the sample, propidium iodide was used as a counterstain, anti-fluorescent stain was added, and the samples were observed under an AXIO confocal fluorescence microscope (Zeiss, Oberkochen, Germany)[37].

For the immunofluorescence experiment, rabbit polyclonal antibodies were prepared against $C p C H S A$. We designed the peptide antigen of $C P C H S A$ by analyzing the $C D N A$ and protein sequences (Additional file 4: Table S4). The peptide was synthesized, and then subcloned into pET-28a-sumo and PGEX-4T-AB1 transfer plasmids. (ABclonal Wuhan, China) synthesized the gene and produced polyclonal antibody. The acquired antibodies were tested to ensure that they met the experimental requirements.

To analyze the localization of the CpCHSA protein, paraffin sections were made from pupae treated with siCHSA or NC. The tissues were fixed in $4 \%$ paraformaldehyde at $4{ }^{\circ} \mathrm{C}$ overnight. Sections were acquired and then deparaffinized using xylene with two washes of $15 \mathrm{~min}$, rehydrated through successive baths of ethanol (100, 96, and 70\% in water, 15 min each), washed twice for $5 \mathrm{~min}$, and then once with PBST (0.01 M phosphate-buffered saline (PBS), pH 7.4 containing $0.1 \%$ Tween 20) for $10 \mathrm{~min}$. The sections were blocked with $2 \%$ bovine serum albumin for $30 \mathrm{~min}$, followed by incubation by anti-CpCHSA antibodies $(1: 100)$ at $4{ }^{\circ} \mathrm{C}$ overnight. The sections were washed and then incubated with Alexa Fluor@ 594conjugated donkey anti-rabbit IgG (Abcam, Cambridge, UK) secondary antibody (1:200 in blocking buffer) for $50 \mathrm{~min}$, in the dark. After three washes in PBST for 5 min each, the nuclei were stained with 4' ,6-diamidino-2-phenylindole (DAPI) for $10 \mathrm{~min}$ in the dark. The sections were then wash with PBST and observed under a fluorescence microscope (Zeiss)[26].

\section{Electron microscopy}

Pupae ( $0-1 \mathrm{~h})$ and adults (12-24 h PE) were injected with siCHSA or NC. At $24 \mathrm{~h}$ after injection of pupae and at $72 \mathrm{~h}$ after injection of the PE adults, tissues were collected and fixed in $4 \%$ paraformaldehyde at 4 ${ }^{\circ} \mathrm{C}$, and then washed with PBS three times for 15 min each. $1 \% \mathrm{OsO}_{4}$ in $0.1 \mathrm{M} \mathrm{PBS}(\mathrm{pH} 7.4)$ was used to post-fix the samples for $2 \mathrm{~h}$ at room temperature. The $\mathrm{OsO}_{4}$ was removed and the samples were rinsed in PBS (0.1 M, pH 7.4) three times for 15 min each. The samples were then dehydrated through successive concentrations of ethanol $(50,70,80,90,95$, and $100 \%$, for $15 \mathrm{~min})$, and finally through two changes of acetone for $15 \mathrm{~min}$, and then infiltrated with 1:1 acetone: EMBed 812 for $3 \mathrm{~h}, 2: 1$ acetone: EMBed 812 overnight, and pure EMBed 812 for $7 \mathrm{~h}$. The samples were kept at $37^{\circ} \mathrm{C}$ overnight and then baked at 60 ${ }^{\circ} \mathrm{C}$ for $48 \mathrm{~h}$. Sections were cut and stained with uranyl acetate for $15 \mathrm{~min}$ followed by lead citrate staining 
for $15 \mathrm{~min}$. The sections were air dried overnight. The ultrastructure of the cuticles was then analyzed using transmission electron microscopy (TEM)[38].

\section{Western blotting}

Western blotting was used to evaluate the specificity of the anti-CpCHSA antiserum and to verify the knockdown efficiency of RNAi. Total proteins were extracted from the whole body of larval, pupal, or adult mosquitoes using Radioimmunoprecipitation assay (RIPA) buffer containing $1 \mathrm{mM}$ phenylmethylsulfonyl fluoride (PMSF) and a protease inhibitor cocktail (Thermo, Rockford, IL, USA), and then centrifuged at $12,000 \times \mathrm{g}$ at $4{ }^{\circ} \mathrm{C}$ for $30 \mathrm{~min}$. A bicinchoninic acid (BCA) protein assay kit (Beyotime, Shanghai, China) was used for protein quantification. The proteins were fractionated using $5 \%$ sodium dodecyl sulfate polyacrylamide gel electrophoresis (SDS-PAGE), and transferred to nitrocellulose membranes. The membranes were probed using anti-CpCHSA (1:1000) and $\beta$-actin (Abclonal 1:7000) antibodies, followed by incubation with labeled secondary antibodies and visualization of the immunoreactive protein bands. The bands were analyzed using Image $\mathrm{J}$ software ( $\mathrm{NIH}$, Bethesda, MA, USA).

\section{Statistical analysis}

SPSS 23.0 (IBM Corp., Armonk, NY, USA) and GraphPad Prism 6.0 software (GraphPad Software Inc., La Jolla, CA, USA) were used for statistical analyses[37]. The statistical significance of the RNAi knockdown efficiency and the survival rate were analyzed using an unpaired Student's $t$ test. ${ }^{*} p<0.05,{ }^{*} p<0.01$, and $\star \star \star p<0.001$. All experiments were performed using at least three independent cohorts.

\section{Results}

\section{CPCHSA cDNA}

The $C p C H S A$ cDNA was isolated using RACE-PCR to amplify the 5 ' and 3 ' regions (Figure 1). The fulllength CpCHSA cDNA (GenBank ID: MH013352) comprises 5396 nucleotides, of which 4740 nucleotides encode a putative protein of 1579 amino acid residues with calculated molecular mass of about 179.54 $\mathrm{KDa}$. The $\mathrm{CpCHSA}$ protein contains three predicted domains; an N-terminal domain with seven transmembrane helices, a highly conserved central domain, and a C-terminal domain with an additional seven transmembrane helices. Ten potential N-glycosylation sites were predicted using NetNGlyc 1.0 software from the ExPASy Proteomics website.

\section{CpCHSA expression pattern}

To confirm the role of $C p C H S A$ in $C$. pipiens pallens, we first examined the mRNA expression of $C p C H S A$ in whole eggs (at 0 and $12 \mathrm{~h}$ ), larval instars (1st, 2nd, 3rd, and 4th), pupae (at 0 and $24 \mathrm{~h}$ ), and adults (1- 
$3 \mathrm{~d}) \mathrm{PE}$. The qPCR results indicated that $C p C H S A$ is expressed in all these different developmental stages, with predominant expression in the pupae and adult (Figure 2a). We also examined the tissue-specific expression patterns of $\mathrm{CpCHSA}$. CpCHSA transcripts were significantly enriched in the head, body, and hindgut of the fourth instar larvae (Figure 2b); and in the foregut, leg, wing, and body of 3-d PE female mosquitoes (Figure 2c).

We then examined the pattern of CpCHSA protein expression. Immunohistochemical analysis of paraffinembedded samples was performed using $12 \mathrm{~h}$ and $24 \mathrm{~h}$ pupa (Figure 3 ). In the pupal stage, the CpCHSA protein in RNAi-NC (control) mosquitoes was detected in the eyes and exoskeleton; however, there was almost no expression in the siCHSA group.

\section{RNAi of CpCHSA hinders molting of C. pipiens pallens}

To investigate the impact of $C p C H S A$ on the molting process, we first monitored molting after knockdown of $C p C H S A$ in third instar larvae $(n=50)$ and pupae $(n=50)$. The larvae (Figure 4$)$ and pupae (Figure 5 ) injected with siCHSA displayed a molting defect phenotype at the third to fourth instar, the fourth instar to pupal stage, and the pupal stage to adult stage. Specifically, the old cuticle was incompletely separated from the mosquito body. Adult mosquitoes exhibited prominent deformities of the leg, abdomen, and wings. $\mathrm{CpCHSA-deficient} \mathrm{adults} \mathrm{had} \mathrm{difficulty} \mathrm{righting} \mathrm{themselves} \mathrm{and} \mathrm{taking} \mathrm{off} \mathrm{compared} \mathrm{with} \mathrm{control}$ adults.

In the third instar larvae (Figure 4), RNAi of $C p C H S A$ led to a substantial decrease of $62.9 \%$, (unpaired Student's $t$ test; $p<0.0001$ ) in the expression of the CpCHSA gene at the mRNA level (Figure 4a). Among 50 larvae injected with siCHSA, 23.5\% (unpaired Student's $t$ test; $p=0.0035$ ) died during the molting process from the third instar to the fourth stage (Figure 4c), 31.71\% (unpaired Student's $t$ test; $p=0.0071$ ) of the survivors died during the molting process from the fourth instar to the pupal stage (Figure 4d), $48.7 \%$ (unpaired Student's $t$ test; $p=0.00127$ ) of the survivors died during the molting process from pupal to adult (Figure $4 \mathrm{e}$ ), and $20.1 \%$ of the survivors (unpaired Student's $t$ test; $p=0.00127$ ) died during the PE (Figure 4f). In the pupal stage (Figure 5), RNAi of $C p C H S A$ led to a $58.3 \%$ decrease (unpaired Student's $t$ test; $p<0.0001$ ) in $C p C H S A$ expression at the mRNA level (Figure 5a). Among 50 pupae injected with siCHSA, $90 \%$ (unpaired Student's $t$ test; $p<0.0001$ ) died during the molting process from the pupal stage to the adult stage (Figure $5 c$ ) and $75 \%$ (unpaired Student's $t$ test; $p=0.00103$ ) of the surviving adult mosquitoes exhibited prominent deformities (Figure $5 \mathrm{~d}$ ).

\section{Effect of CpCHSA on chitin metabolism}

To further determine the effect of knockdown of $C p C H S A$ expression on chitin content and the cuticle, we injected siRNA into 0-1 h pupae, and performed chitin staining (Figure 6) and transmission electron microscopy (TEM) (Figure 7) on the abdominal integument at 12 and $24 \mathrm{~h}$ after injection. At 12 and $24 \mathrm{~h}$ after injection, the old cuticle and chitin were separated from the epithelial cell layer in the NC group, while 
in the siCHSA group it was not. The results showed that siCHSA hindered the separation of old chitin from the epithelial cell layer (Figure $6 b$ ), and prevented the separation of the old cuticle from the epithelial cell layer (Figure 7b, and c). At $24 \mathrm{~h}$ after injection, we observed that new cuticle and chitin were formed, and the structure of the old cuticle and chitin was incomplete in the NC group. In the siCHSA group, the formation of new cuticle and chitin was inhibited, and the structure of old cuticle and chitin was complete (Figure 7d, and e). The results showed that knockdown of $C p C H S A$ transcription inhibited the degradation of the old cuticle and the formation of new cuticle, which was caused by diminished chitin synthesis and degradation. RNAi resulted in the rigid structure of the old cuticle being more complete than that of the NC group, which would obstruct shedding of the old cuticle during molting.

\section{CpCHSA is required for the cuticle}

The cuticle of insect consists of the envelope, epicuticle, and procuticle [39]. The procuticle can be further divided into the exocuticle, endocuticle and mesocuticle, with horizontally-aligned chitin-protein rich laminae $[40,41]$. We observed the effect of siCHSA on the ultrastructure of the cuticle using TEM (Figure 8). Injection of siCHSA into third instar larval and $0-1 \mathrm{~h}$ pupal mosquitoes did not prevent all pupae from molting. The structure of the cuticle in the abdomen of RNAi mosquitoes had looser and less compact laminae compared with that of the control at 1-day posteclosion (Figure 8 b, and c). In addition, knockdown of $\mathrm{CpCHSA}$ resulted in an irregular leg structure and indistinct boundaries in the procuticle, whereas the leg of $\mathrm{NC}$ exhibited a normally organized, complete structure with uniform thickness (Figure 8c).

\section{CpCHSA-deficiency results in abnormal adult cuticle}

To further assess the function of $C p C H S A$ in the adult mosquito, we injected siCHSA into one day PE mosquitoes. However, no significant morphological abnormalities nor a different survival rate were observed in either the siCHSA or NC group (Figure 9). In contrast, at $3 \mathrm{~d} \mathrm{PE}$, the ultrastructure of endocuticle of leg from siCHSA-treated insects was abnormal. As reported in several other insects, two distinct layers of chitin have been reported in the epidermis after adult molting. One, called the "mesocuticle", forms underneath the exocuticle after adult eclosion, and the other, called the "endocuticle", continues to be deposited below the mesocuticle. To analyze whether CpCHSA deficiency affects the ultrastructure of the mesocuticle and endocuticle, the leg cuticle microstructure of adults aged $1 \mathrm{~d}$ and $3 \mathrm{~d}$ were detected. At 3 days after eclosion, the cuticle of the leg of the WT insect contained a mesocuticle and endocuticle with a normal appearance. In contrast, the mosquitoes treated with siCHSA had only mesoderm at the corresponding stage, with no apparent endoderm structure (Figure 10).

\section{Discussion}

Research on the relevance of chitin to molting been documented in many insect species of insects; however, related information in mosquitoes is limited $[6,26,32]$. CHSA is a key enzyme in the synthesis of 
chitin, which is important for the development and growth of insects. In the present study, knockdown CpCHSA in C. pipiens pallens resulted in failure of the molting process, and failure of the cuticle structural integrity in adult mosquitoes, which suggested that CHSA is essential for the growth and development of mosquitoes. $C p C H S A$ is expressed in the cuticle during molting, which has been well documented in insects [22]. In our study, CpCHSA expression was not limited to the molting process and cuticle, but was detected at all developmental stages and in all tissues. The expression of $C p C H S A$ was highest in the pupal stage, followed by that in the adult mosquito. Further analysis showed that the expression of CPCHSA was higher mainly in the exoskeletons of larvae and non-blood meal fed female mosquitoes. Immunohistochemistry showed that CpCHSA was mainly expressed in the cuticle. Taken together, these results prompted us to hypothesize that, in addition to a role in the cuticle during molting, CpCHSA might also be required to ensure normal growth and development of the body and physiological functions in mosquitoes.

RNA interference was applied at different developmental stages of $C$. pipiens pallens to study the function of $\mathrm{CpCHSA}$ systematically. Lethal phenotypes were observed in mosquitoes treated with RNAi for $C p C H S A$ at most developmental stages. $C p C H S A$ appears to be indispensable in the process of molting. Treatment with siCHSA led to the death of mosquitoes at the time of molting, and the death rate was highest in the pupal-adult stage, in which almost all pupae died as pharate adults entrapped in the old pupal cuticle, and defects in surviving adult mosquitoes were also observed. These results suggested that that $\mathrm{CpCHSA}$ has an essential role in molting. It is generally believed that the absence of CHSA causes a chitin synthesis disorder, which affects the formation of new cuticle and leads to the death of the insects in the molting stage [39]. However, by chitin staining, we observed a reduction of the chitin content in the new cuticle and increased chitin in the old cuticle of the abdomen cuticle after RNAi of CpCHSA compared with that in the controls. The old chitin could not be separated from the epidermis after RNAi of $C p C H S A$, and the old chitin was thicker after injection of siCHSA compared with the controls. A TEM study of the pupal abdominal cuticle also showed the same phenomena. The cuticle consists of many thin layers with alternating dense layers. In the siCHSA group, the old cuticle was compact and intact. It extended directly from the apical membrane of the basal epidermal cells to the epidermis. In contrast, the old cuticle ultrastructure was disrupted in the NC group insects. The inner and intermediate areas of the cuticle showed thin, unorganized sections with low compactness. The siCHSA group showed thinner new cuticle, and the new and old epidermis could not be separated. Chitin degradation disorders result in dense and hard old epidermis, which inhibits shedding during molting. During development, insects must periodically molt to accommodate growth and overcome the rigid constraints imposed by the chitin exoskeleton. The molting process begins when the epidermis secretes the outer layer of the new cuticle, separating the epidermis from the overlying old cuticle. A "dissolution space" is then formed to separate the new (internal) cuticle from the old (external) cuticle. The old cuticle is qualitatively digested by chitinases, and then falls off to promote the molting process as the exuvia during a molt; the chitin in the new cuticle is promoted by chitin synthetase-mediated synthesis, which facilitates insect survival [37]. These results suggested that CpCHSA is essential for the degradation of the old chitin and old epidermis and the formation of the new chitin and new epidermis during molting. 
This unexpected finding suggests that CHSA is not only involved in the process of molting, but may also affects chitin degradation. Chitin synthases are involved in chitin synthesis, and chitinases are involved in chitin degradation, which are two different processes. One possibility is that CHSA can affect the degradation of chitin; however, further proof is needed. RNAi for CPCHSA did not result in $100 \%$ molting failure and approximately $10 \%$ the adults survived. The surviving adult insects had malformed wings, legs, and abdomens. We also observed a reduction in the thickness and a loss of organization of both the abdomen and leg after RNAi for CpCHSA compared with those in the controls, which would affect cuticle rigidity. Taken together, $\mathrm{CpCHSA}$ is essential for the molting process. Therefore, we could control the adult mosquito population and reduce the spread of disease by inhibiting the expression of CHSA in the larval or pupal stages.

The application of siCHSA in larval and pupal stages significantly reduced the thickness and density of the cuticle layer in the abdomen and legs of adult mosquitoes compared with those in the control group. In the qPCR results, $C P C H S A$ was observed to be highly expressed in the wings and legs of adult mosquitoes. Therefore, we investigated the function of $\mathrm{CpCHSA}$ in the adult stage. Silencing $\mathrm{CpCHSA}$ did not result in mortality and deformity during adult development. We hypothesized that knockdown CpCHSA would cause changes in the microstructures of the adult cuticle. As reported in several other species of beetles [39], two distinct layers of chitin have been reported in the cuticle after adult molting. One is called the "mesocuticle", which forms beneath the exocuticle one day after adult ecdysis, and the other is called the "endocuticle", which continues to deposit beneath the mesocuticle two days after adult ecdysis. To analyze the structure and composition of the cuticle of adult mosquitoes, the leg anatomy of wild-type $1 \mathrm{~d}$ - and $3 \mathrm{~d}$-old adult mosquitoes was observed using TEM. We observed that the cuticle of the leg of the 3-d PE mosquito had obvious mesocuticle and endocuticle. In contrast, the siCHSA-treated insects lacked the endocuticle structure, and the exocuticle contained more pore canals, such that the cuticle cannot form a dense layered structure. The thickness and structure of the epidermis have been reported to be related to adult development. An intact cuticle structure helps the insect resist external pressure $[42,43]$. The results of the present study showed that CpCHSA is essential for the formation of intact and dense cuticle structures of adult mosquitoes.

\section{Conclusion}

CpCHSA defects lead not only to fatal developmental malformation, but also affect cuticle development in the adult stage. In the present study, we provided a description of the effect of CpCHSA in the larvae, pupae, and adults of $C$. pipiens pallens, suggesting that CHSA has a broader effect on insects than previously thought. Chitin inhibitors are controversial because of their non-specificity, thus CHSA could be used as a new target to kill mosquitoes more efficiently and safely throughout their growth cycle. If successful, these approaches could eventually reduce the spread of mosquito-borne viral infections.

\section{Abbreviations}


CHSA, chitin synthase A; CHSB, chitin synthase B; RNAi, RNA interference; siRNA, small interfering RNA; WT, wild-type; NC, negative control; qPCR, quantitative real time PCR; PU, pupae; PE, posteclosion; $A D$, adult; L3, the third instar larvae; L4, the fourth instar larvae; SEM standard error of the mean; TEM, transmission electron microscopy; PBM, post-blood meal; WT, wild-type; C. pipiens pallens, Culex pipiens pallens.

\section{Declarations}

\section{Acknowledgments}

Not applicable

\section{Funding}

This work was supported by the National Natural Science Foundation of China (grant No. 81772227, 81672056 and 81672058) and the National S \& T Major Program (grant No. 2017ZX10303404-002-006).

\section{Competing interests}

The authors declare that they have no competing interests.

\section{Ethics approval}

All animal procedures were approved by the Institutional Animal Care and Use Committee (IACUC) of Nanjing Medical University for the Use of Laboratory Animals (Protocol No. 582/2017).

\section{Consent for publication}

Not applicable.

\section{Availability of data and materials}

All data are fully available without restriction.

\section{Author Contributions}

BS, DZ performed the conceptualization; BS, DZ, YS, LM responsible for data curation; XSY, YX, QY, HBZ, HTN provided for data acquisition; DZ and XSY carried out date analysis and manuscript editing. All 
authors have read and approved the manuscript for submission.

\section{References}

1. Castilho CJ, Li D, Liu M, Liu Y, Gao H, Hurt RH: Mosquito bite prevention through graphene barrier layers. Proc Natl Acad Sci USA 2019, 116(37):18304-18309. https://doi.org/10.1073/pnas.1906612116. PubMed PMID: 31451645.

2. Ling L, Raikhel AS: Serotonin signaling regulates insulin-like peptides for growth, reproduction, and metabolism in the disease vector. Proc Natl Acad Sci USA 2018, 115(42):E9822-E9831. 2018;115(42): E9822-E31. https://doi.org/10.1073/pnas.1808243115. PubMed PMID: 30275337.

3. Le Coupanec A, Tchankouo-Nguetcheu S, Roux P, Khun H, Huerre M, Morales-Vargas R, Enguehard M, Lavillette D, Misse D, Choumet V: Co-Infection of Mosquitoes with Chikungunya and Dengue Viruses Reveals Modulation of the Replication of Both Viruses in Midguts and Salivary Glands of Aedes aegypti Mosquitoes. Int J Mol Sci. 2017 Aug 4;18(8). PubMed PMID: 28777313. https://doi.org/ 10.3390/ijms18081708. Pubmed Central PMCID: 5578098.

4. Chiodini J: Apps from the World Health Organization - The World Malaria Report and more. Travel med Infect Dis. 2018 Mar - Apr; 22:82-4. https://doi.org/10.1016/j.tmaid.2018.03.007. PubMed PMID: 29608969.

5. Farnesi LC, Menna-Barreto RFS, Martins AJ, Valle D, Rezende GL: Physical features and chitin content of eggs from the mosquito vectors Aedes aegypti, Anopheles aquasalis and Culex quinquefasciatus: Connection with distinct levels of resistance to desiccation. J Insect Physiol. 2015; 83:43-52. https://doi.org/10.1016/j.jinsphys.2015.10.006 PubMed PMID: 26514070.

6. Lopez SBG, Guimarães-Ribeiro V, Rodriguez JVG, Dorand FAPS, Salles TS, Sá-Guimarães TE, Alvarenga ESL, Melo ACA, Almeida RV, Moreira MF: RNAi-based bioinsecticide for Aedes mosquito control. Sci Rep. 2019;9(1):4038. https://doi.org/10.1038/s41598-019-39666-5. PubMed PMID: 30858430.

7. Tian X, Zhang C, Xu Q, Li Z, Shao X: Azobenzene-benzoylphenylureas as photoswitchable chitin synthesis inhibitors. Org Biomol Chem. 2017 Apr 11;15(15):3320-3.

https://doi.org/10.1039/c6ob02813f PubMed PMID: 28362014.

8. Sun R, Liu C, Zhang H, Wang Q: Benzoylurea Chitin Synthesis Inhibitors. J Agric food Chem. 2015 Aug 12;63(31):6847-65. https://doi.org/10.1021/acs.jafc.5b02460. PubMed PMID: 26168369.

9. Liu X, Zhang H, Li S, Zhu KY, Ma E, Zhang J: Characterization of a midgut-specific chitin synthase gene (LmCHS2) responsible for biosynthesis of chitin of peritrophic matrix in Locusta migratoria. Insect biochem Mol Biol. 2012 Dec;42(12):902-10. https://doi.org/10.1016/j.ibmb.2012.09.002. PubMed PMID: 23006725.

10. Liu H, Xie L, Cheng P, Xu J, Huang X, Wang H, Song X, Liu L, Wang H, Kou J et al: Trends in insecticide resistance in Culex pipiens pallens over 20 years in Shandong, China. Parasites \& vectors. 2019 Apr 11;12(1):167. https://doi.org/10.1186/s13071-019-3416-9. PubMed PMID: 30975185. Pubmed Central PMCID: 6460514. 
11. Zhang J, Lu A, Kong L, Zhang Q, Ling E: Functional analysis of insect molting fluid proteins on the protection and regulation of ecdysis. J Bioll Chem. 2014 Dec 26;289(52):35891-906. https://doi.org/10.1074/jbc.M114.599597. PubMed PMID: 25368323. Pubmed Central PMCID: 4276858.

12. Zhang J, Zhu KY: Characterization of a chitin synthase cDNA and its increased mRNA level associated with decreased chitin synthesis in Anopheles quadrimaculatus exposed to diflubenzuron. Insect biochem Mol Biol. 2006 Sep;36(9):712-25. https://doi.org/10.1016/j.ibmb.2006.06.002. PubMed PMID: 16935220.

13. Ling L, Kokoza VA, Zhang C, Aksoy E, Raikhel AS: MicroRNA-277 targets insulin-like peptides 7 and 8 to control lipid metabolism and reproduction in Aedes aegypti mosquitoes. Proc Natl Acad Sci U S A. 2017 Sep 19;114(38): E8017-E24. https://doi.org/10.1073/pnas.1710970114. PubMed PMID: 28874536. Pubmed Central PMCID: 5617303.

14. Chiang YN, Tan KJ, Chung H, Lavrynenko O, Shevchenko A, Yew JY: Steroid Hormone Signaling Is Essential for Pheromone Production and Oenocyte Survival. PLoS genetics. 2016 Jun;12(6): e1006126. https://doi.org/10.1371/journal.pgen.1006126. Pubmed Central PMCID: 4917198.

15. Konno K, Shimura S, Ueno C, Arakawa T, Nakamura M: Abnormal swelling of the peritrophic membrane in Eri silkworm gut caused by MLX56 family defense proteins with chitin-binding and extensin domains. Phytochemistry. 2018 Mar; 147:211-9. https://doi.org/10.1016/j.phytochem.2018.01.005. PubMed PMID: 29406091.

16. Zhao X, Qin Z, Liu W, Liu X, Moussian B, Ma E, Li S, Zhang J: Nuclear receptor HR3 controls locust molt by regulating chitin synthesis and degradation genes of Locusta migratoria. Insect biochem Mol Biol. 2018 Jan; 92:1-11. https://doi.org/10.1016/j.ibmb.2017.11.001. PubMed PMID: 29113754.

17. Dias RO, Cardoso C, Pimentel AC, Damasceno TF, Ferreira C, Terra WR: The roles of mucus-forming mucins, peritrophins and peritrophins with mucin domains in the insect midgut. Insect Mol Biol. 2018 Feb;27(1):46-60. https://doi.org/10.1111/imb.12340. PubMed PMID: 28833767.

18. Tetreau G, Wang P: Chitinous Structures as Potential Targets for Insect Pest Control. Adv Exp Med Biol. 2019; 1142:273-92. https://doi.org/10.1007/978-981-13-7318-3_13. PubMed PMID: 31102251.

19. Xi Y, Pan PL, Ye YX, Yu B, Zhang CX: Chitin deacetylase family genes in the brown planthopper, Nilaparvata lugens (Hemiptera: Delphacidae). Insect Mol Biol. 2014;23(6):695-705. https://doi.org/10.1111/imb.12113. PubMed PMID: 24989071.

20. Vidhate RP, Bhide AJ, Gaikwad SM, Giri AP: A potent chitin-hydrolyzing enzyme from Myrothecium verrucaria affects growth and development of Helicoverpa armigera and plant fungal pathogens. Int J Biol Macromol. 2019; 141:517-28. https://doi.org/10.1016/j.ijbiomac.2019.09.031. PubMed PMID: 31494159.

21. Kaya M, Sofi K, Sargin I, Mujtaba M: Changes in physicochemical properties of chitin at developmental stages (larvae, pupa and adult) of Vespa crabro (wasp). Carbohydr Polym. 2016; 145:64-70. https://doi.org/10.1016/j.carbpol.2016.03.010. PubMed PMID: 27106152. 
22. Mansur JF, Alvarenga ES, Figueira-Mansur J, Franco TA, Ramos IB, Masuda H, Melo AC, Moreira MF: Effects of chitin synthase double-stranded RNA on molting and oogenesis in the Chagas disease vector Rhodnius prolixus. Insect biochem Mol Biol. 2014 Aug; 51:110-21. https://doi.org/10.1016/j.ibmb.2013.12.006. PubMed PMID: 24398146.

23. Mohammed AMA, Diab MR, Abdelsattar M, Khalil SMS: Characterization and RNAi-mediated knockdown of Chitin Synthase A in the potato tuber moth, Phthorimaea operculella. Sci Rep. 2017 Aug 25;7(1):9502. https://doi.org/10.1038/s41598-017-09858-y. PubMed PMID: 28842624. Pubmed Central PMCID: 5573318.

24. Qu M, Yang Q: A novel alternative splicing site of class A chitin synthase from the insect Ostrinia furnacalis - gene organization, expression pattern and physiological significance. Insect biochem Mol Biol. 2011;41(12):923-31. https://doi.org/10.1016/j.ibmb.2011.09.001. PubMed PMID: 21933709.

25. Moreira MF, Dos Santos AS, Marotta HR, Mansur JF, Ramos IB, Machado EA, Souza GH, Eberlin MN, Kaiser CR, Kramer KJ et al: A chitin-like component in Aedes aegypti eggshells, eggs and ovaries. Insect biochem Mol Biol. 2007 Dec;37(12):1249-61. https://doi.org/10.1016/j.ibmb.2007.07.017. PubMed PMID: 17967344.

26. Zhang X, Zhang J, Park Y, Zhu KY: Identification and characterization of two chitin synthase genes in African malaria mosquito, Anopheles gambiae. Insect biochem Mol Biol. 2012 Sep;42(9):674-82. https://doi.org/10.1016/j.ibmb.2012.05.005 PubMed PMID: 22683441. Pubmed Central PMCID: 3489263.

27. Yang W-J, Xu K-K, Cong L, Wang J-J: Identification, mRNA expression, and functional analysis of chitin synthase 1 gene and its two alternative splicing variants in oriental fruit fly, Bactrocera dorsalis. Int J Biol Sci. 2013;9(4):331-42. https://doi.org/10.7150/ijbs.6022 PubMed PMID: 23569438.

28. Zhang J, Liu X, Zhang J, Li D, Sun Y, Guo Y, Ma E, Zhu KY: Silencing of two alternative splicingderived mRNA variants of chitin synthase 1 gene by RNAi is lethal to the oriental migratory locust, Locusta migratoria manilensis (Meyen). Insect biochem Mol Biol. 2010 Nov;40(11):82433. https://doi.org/10.1016/j.ibmb.2010.08.001. PubMed PMID: 20713155.

29. Khajuria C, Buschman LL, Chen MS, Muthukrishnan S, Zhu KY: A gut-specific chitinase gene essential for regulation of chitin content of peritrophic matrix and growth of Ostrinia nubilalis larvae. Insect biochem Mol Biol. https://doi.org/10.1016/j.ibmb.2010.06.003 2010 Aug;40(8):621-9. PubMed PMID: 20542114.

30. Zhu Q, Arakane Y, Beeman RW, Kramer KJ, Muthukrishnan S: Functional specialization among insect chitinase family genes revealed by RNA interference. Proc Natl Acad Sci U S A. 2008 May 6;105(18):6650-5. https://doi.org/10.1073/pnas.0800739105. PubMed PMID: 18436642. Pubmed Central PMCID: 2373347.

31. Arakane Y, Specht CA, Kramer KJ, Muthukrishnan S, Beeman RW: Chitin synthases are required for survival, fecundity and egg hatch in the red flour beetle, Tribolium castaneum. Insect biochem Mol 
Biol. 2008; 38(10):959-62. https://doi.org/10.1016/j.ibmb.2008.07.006. PubMed PMID: 18718535.

32. Zimoch L, Hogenkamp DG, Kramer KJ, Muthukrishnan S, Merzendorfer H: Regulation of chitin synthesis in the larval midgut of Manduca sexta. Insect biochem Mol Biol. 2005;35(6):515-27. https://doi.org/10.1016/j.ibmb.2005.01.008. PubMed PMID: 15857758.

33. Lee J-B, Kim HS, Park Y: Down-regulation of a chitin synthase a gene by RNA interference enhances pathogenicity of Beauveria bassiana ANU1 against Spodoptera exigua (HÜBNER). Arch Insect Biochem Physiol. 2017;94(2). https://doi.org/10.1002/arch.21371. PubMed PMID: 28094453.

34. Yang W-J, Xu K-K, Yan X, Chen C-X, Cao Y, Meng Y-L, Li C: Functional characterization of chitin deacetylase 1 gene disrupting larval-pupal transition in the drugstore beetle using RNA interference. Comp Biochem Physiol B, Biochem Mol Biol. 2018;219-220:10-6. https://doi.org/10.1016/j.cbpb.2018.03.001. PubMed PMID: 29555304.

35. Chang KS, Kim HC, Klein TA, Ju YR: Insecticide resistance and cytochrome-P450 activation in unfed and blood-fed laboratory and field populations of Culex pipiens pallens. Journal of pest science. 2017;90(2):759-71. https://doi.org/10.1007/s10340-016-0820-1. PubMed PMID: 28275327. Pubmed Central PMCID: 5320006.

36. Livak KJ, Schmittgen TD: Analysis of relative gene expression data using real-time quantitative PCR and the 2(-Delta Delta C(T)) Method. Methods. 2001 Dec;25(4):402-8. https://doi.org/10.1006/meth.2001.1262. PubMed PMID: 11846609.

37. Yang $M$, Wang $Y$, Jiang $F$, Song $T$, Wang $H$, Liu Q, Zhang J, Zhang J, Kang L: miR-71 and miR-263 Jointly Regulate Target Genes Chitin synthase and Chitinase to Control Locust Molting. PLoS genetics. 2016 Aug;12(8):e1006257. https://doi.org/10.1371/journal.pgen.1006257. PubMed PMID: 27532544. Pubmed Central PMCID: 4988631.

38. Suman DS, Shrivastava AR, Parashar BD, Pant SC, Agrawal OP, Prakash S: Variation in morphology and morphometrics of eggs of Culex quinquefasciatus mosquitoes from different ecological regions of India. J Vector Ecol. 2009;34(2):191-9. https://doi.org/ 10.1111/j.1948-7134.2009.00026.x. PubMed PMID: 20836822.

39. Noh MY, Muthukrishnan S, Kramer KJ, Arakane Y: A chitinase with two catalytic domains is required for organization of the cuticular extracellular matrix of a beetle. PLoS genetics. 2018 Mar;14(3):e1007307. https://doi.org/10.1371/journal.pgen.1007307. PubMed PMID: 29590098. Pubmed Central PMCID: 5891080.

40. Noh MY, Muthukrishnan S, Kramer KJ, Arakane Y: Cuticle formation and pigmentation in beetles. Curr Opin Insect Sci. 2016; 17:1-9. https://doi.org/10.1016/j.cois.2016.05.004. PubMed PMID: 27720067.

41. Mun S, Noh MY, Dittmer NT, Muthukrishnan S, Kramer KJ, Kanost MR, Arakane Y: Cuticular protein with a low complexity sequence becomes cross-linked during insect cuticle sclerotization and is required for the adult molt. Sci Rep. 2015; 5:10484. https://doi.org/10.1038/srep10484. PubMed PMID: 25994234.

42. Wang L-Y, Jafarpour M, Lin C-P, Appel E, Gorb SN, Rajabi H: Endocuticle sclerotisation increases the mechanical stability of cuticle. Soft Matter. 2019;15(41):8272-8. 
https://doi.org/10.1039/c9sm01687b. PubMed PMID: 31553024.

43. Rasheed H, Ye C, Meng Y, Ran Y, Li J, Su X: Comparative transcriptomic analysis and endocuticular protein gene expression of alate adults, workers and soldiers of the termite Reticulitermes aculabialis. BMC genomics. 2019 Oct 15;20(1):742. https://doi.org/10.1186/s12864-019-6149-4. PubMed PMID: 31615402. Pubmed Central PMCID: 6794787.

\section{Figures}




\section{Figure 1}

Nucleotide and deduced amino acid sequences of CpCHSA from Culex pipiens pallens (MH013352). The stop codon (TAA) is indicated by an asterisk $\left(^{*}\right)$ and marked in black. The putative polyadenylation signal (AATAA) is marked in black. The amino acid sequence of the putative catalytic domain is colored gray with a black background. The signature motifs (EDR and QRRRW) have a black background, and the putative $\mathrm{N}$-glycosylation sites are underlined 

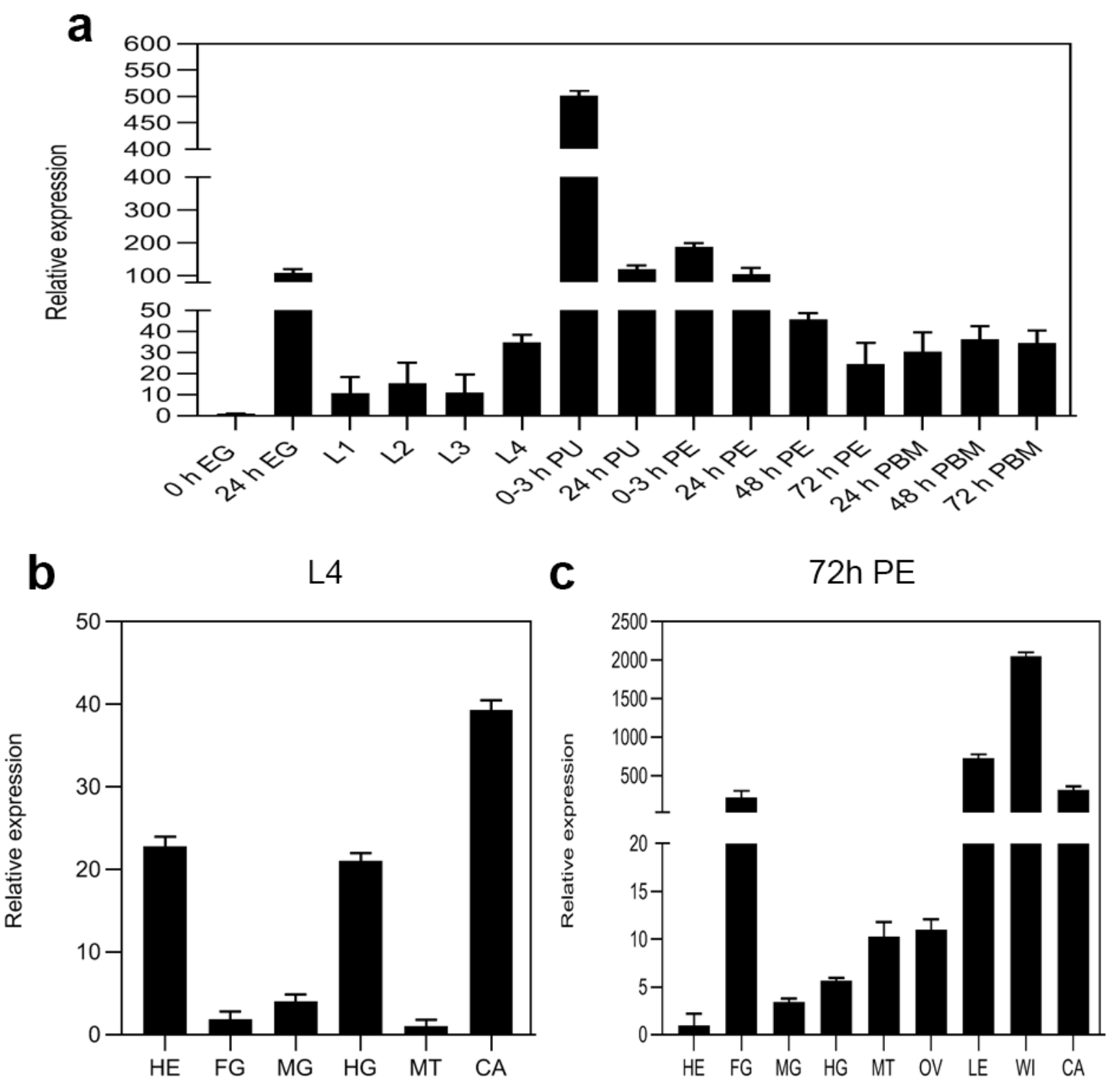

Figure 2

CpCHSA gene expression patterns. Relative expression levels of $\mathrm{CpCHSA}$ in different stages and different tissues, as assessed using qPCR. (a) Different stages include egg (EG), larvae (L1-4), pupae (PU), posteclosion (PE), and post-blood meal (PBM). Tissues include the head (HE), foregut (FG), midgut (MG), hindgut (HG), Malpighian tubules (MT), ovary (OV), leg (LE), wing (WI), and carcass (CA). Relative expression level of CpCHSA in (b) fourth instar larvae, (c) $72 \mathrm{~h}$ PE stage. The ACTB ( $\beta$-actin) gene was used as an internal reference. Relative expression levels were calculated based on the lowest expression value, which was ascribed an arbitrary value of 1 . Data are the means \pm SEM of three biological replicates 
a

PU

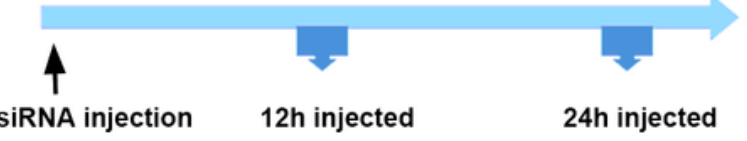

b

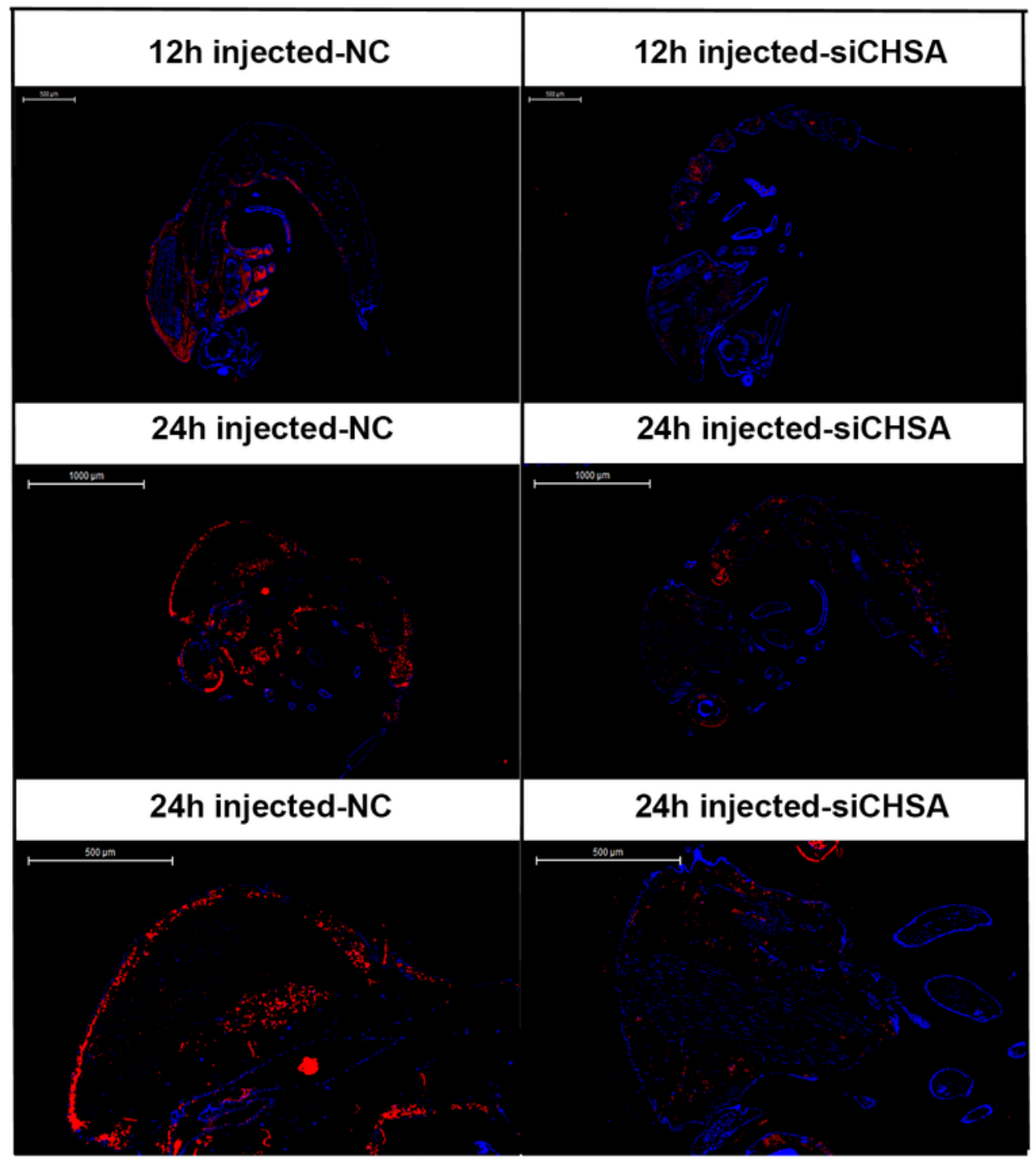

Figure 3

CpCHSA protein localization. Immunofluorescence analysis was performed to determine the location of CpCHSA in pupal stages. (a) RNAi of CpCHSA in the pupal stage. (b) Cryosections of pupae that had been injected with siCHSA or NC were incubated with the anti-CpCHSA antibody (red) 

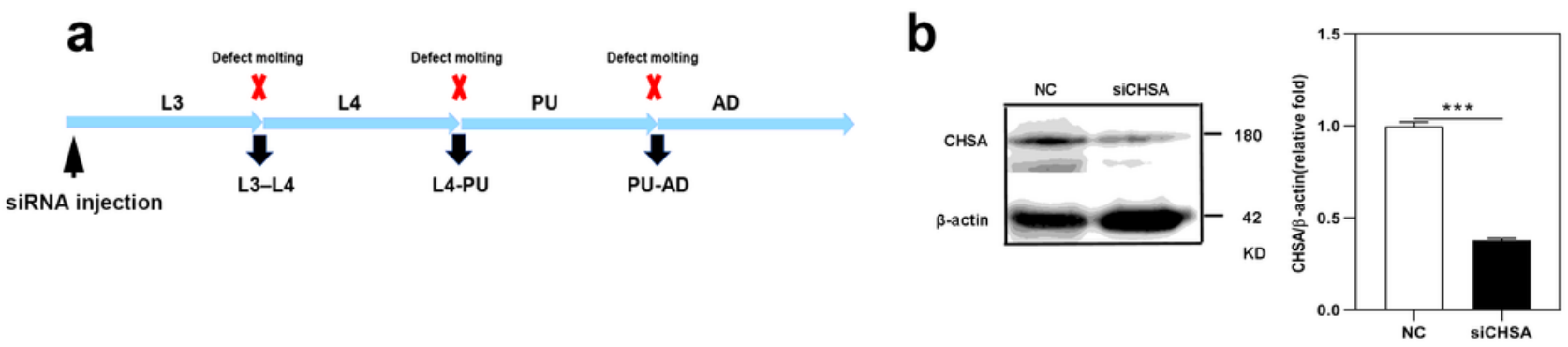

C
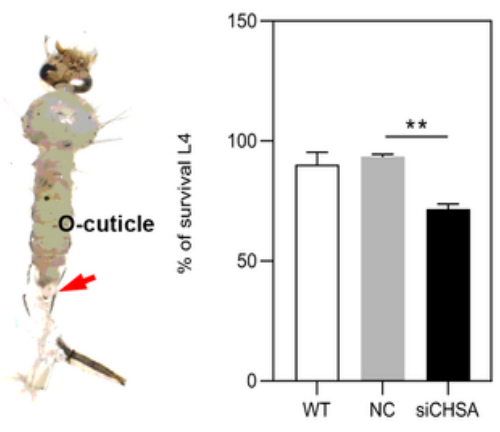

e

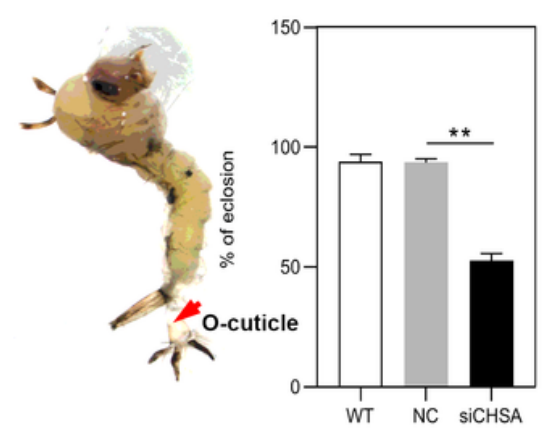

d
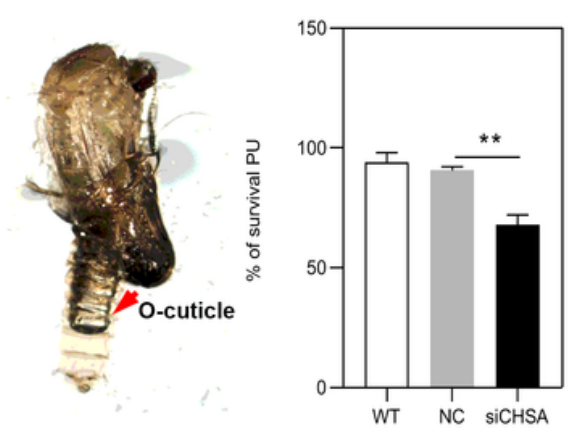

f

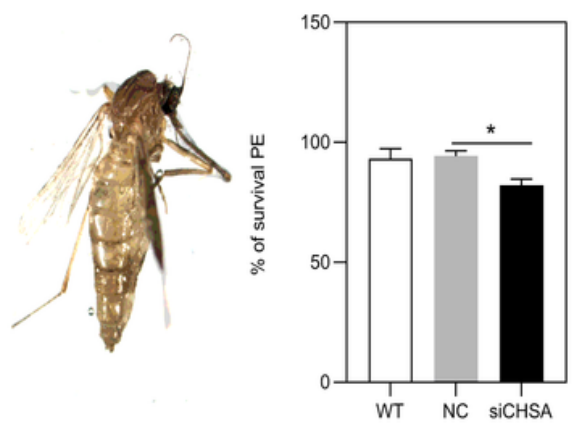

\section{Figure 4}

Phenotypes produced by RNAi of CpCHSA in the larvae stage. (a) Schematic diagram of the effect of siCHSA treatment on the moulting phenotype. The red arrow indicates the shedding old cuticle in the defective moulting process. (b) RNAi of CpCHSA in third instar larvae. Expression levels of CpCHSA at 72 $\mathrm{h}$ after injecting siCHSA, as assessed using western blotting. (c) siCHSA injection into third instar larvae reduce the survival rate of fourth instar larvae. (d) The survival rate of fourth instar larvae to the pupal stage. (e) The eclosion rate of pupae. (f) The survival rate of PE mosquitoes. Data represent three biological replicates (50 individuals in each replicate) with three technical replicates, and results are shown as the mean \pm SEM ( $\left.{ }^{*} p<0.05,{ }^{*} p<<0.01, * \star * p<0.001\right)$. PU, pupae; $A D$, adult; $L 3$, the third instar larvae; L4, the fourth instar larvae; O-cuticle, old cuticle; PE, posteclosion 
a

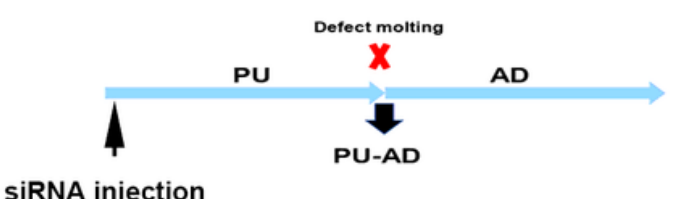

siRNA injection

C

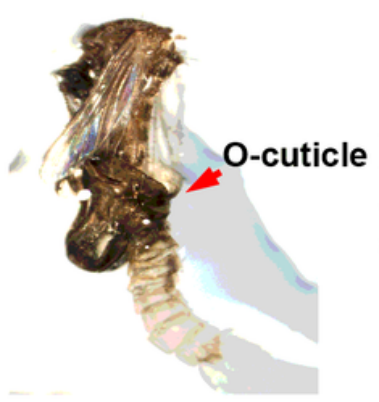

b

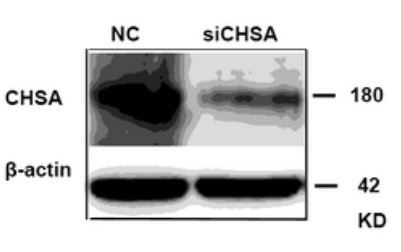

KD

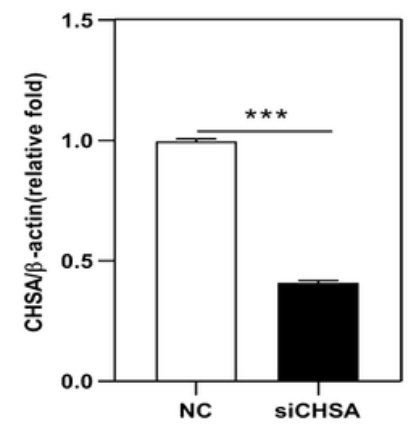

d
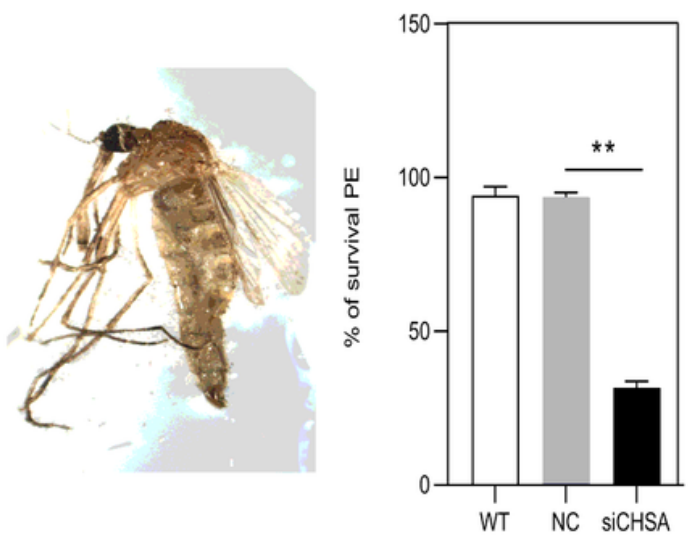

Figure 5

Phenotypes produced by RNAi of CpCHSA in the pupal stage. (a) Schematic diagram of siCHSA treatment in the $0-1 \mathrm{~h}$ pupae. (b) Levels of CpCHSA at $24 \mathrm{~h}$ after injecting siCHSA; CpCHSA protein levels were determined using western blotting analysis with a CpCHSA-specific polyclonal antibody. (c) siCHSA injection into pupae reduced the eclosion rate; (d) The survival rate of PE mosquitoes. All surviving individuals were used for measurement. Data represent three biological replicates (50 individuals in each replicate) with three technical replicates, and the results are shown as the mean \pm SEM $\left({ }^{\star} p<0.05\right.$, **p $<0.01$, $\left.{ }^{\star \star \star} \mathrm{p}<0.001\right)$. PU, pupae; AD, adult; O-cuticle, old cuticle; PE, posteclosion 
a

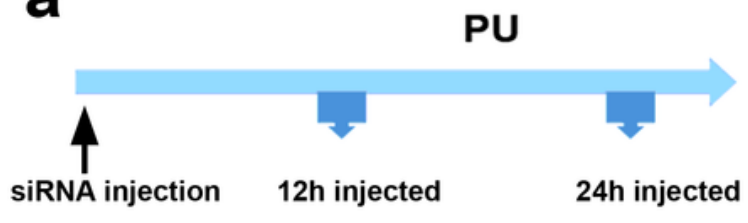

b

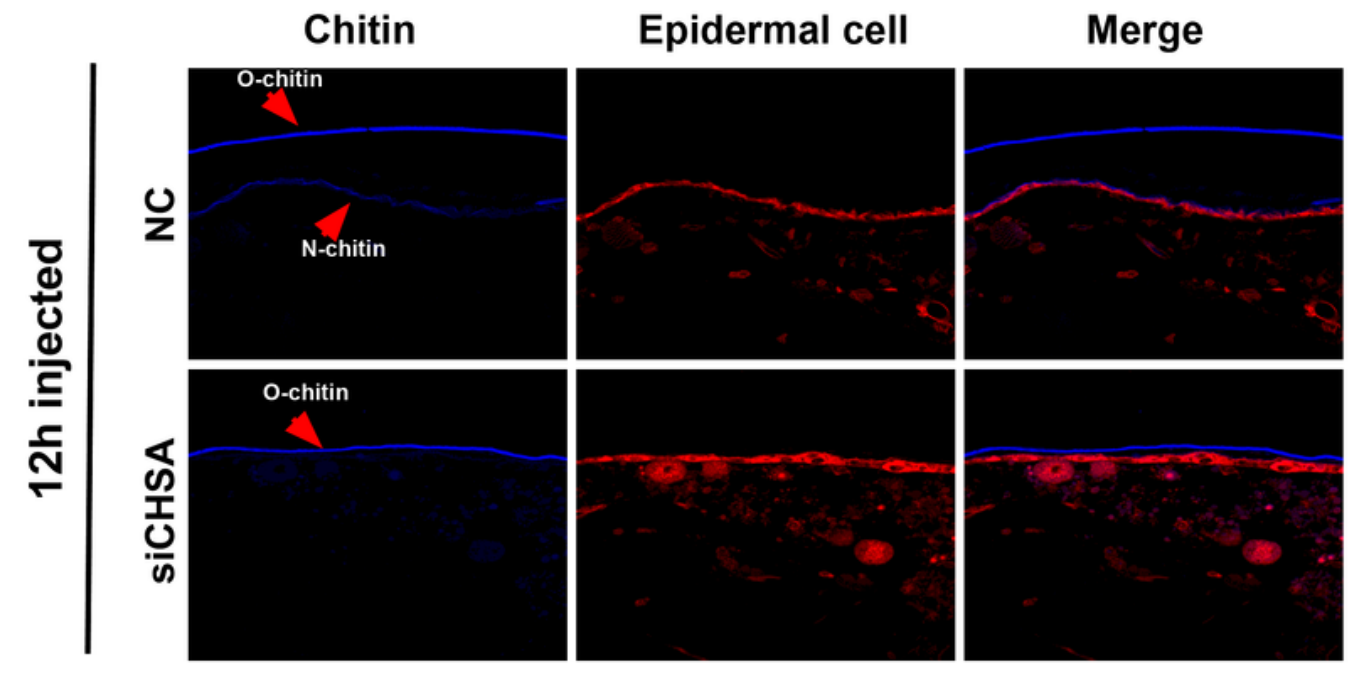

C

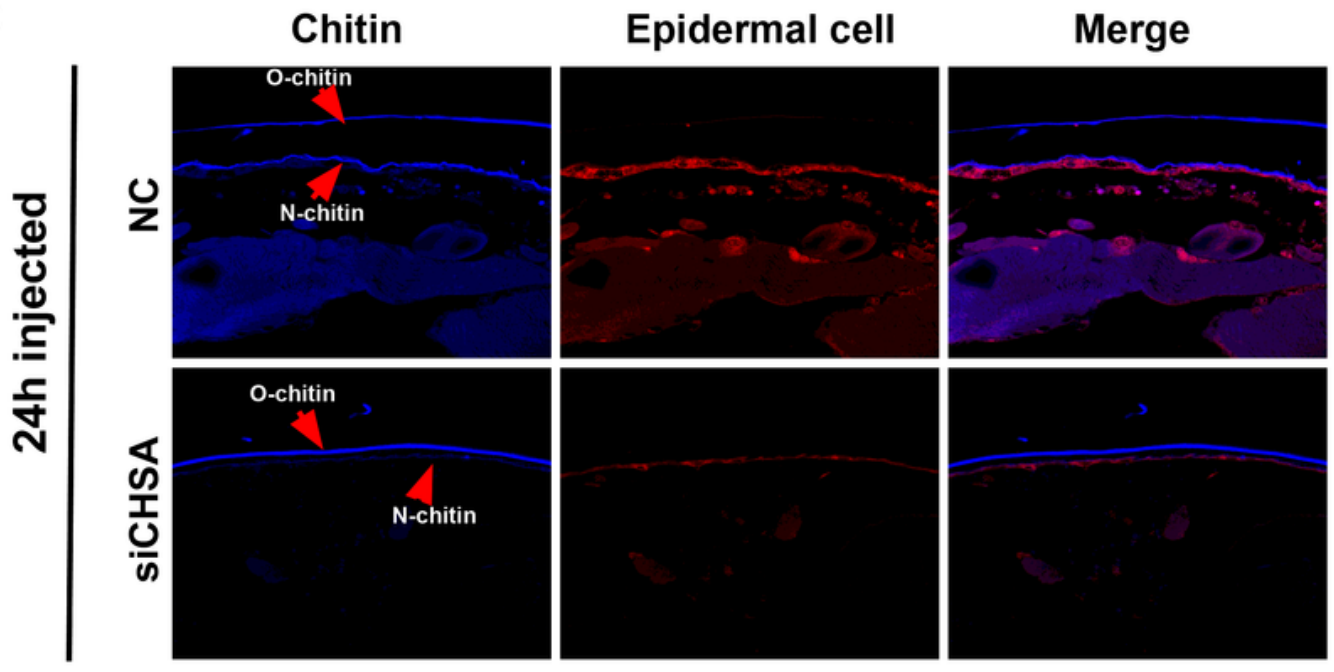

\section{Figure 6}

Effect of CpCHSA on the chitin metabolism of the new and old chitin. (a) RNAi of CpCHSA in the pupal stage; the abdomen of pupa was detected. The red arrow indicates the chitin position. The chitin staining experiment in the integument was performed by injecting siCHSA or NC into the pupae after $12 \mathrm{~h}(\mathrm{~b})$, and $24 \mathrm{~h}$ (c). O-chitin, old chitin; N-chitin, new chitin 
a

\section{PU}
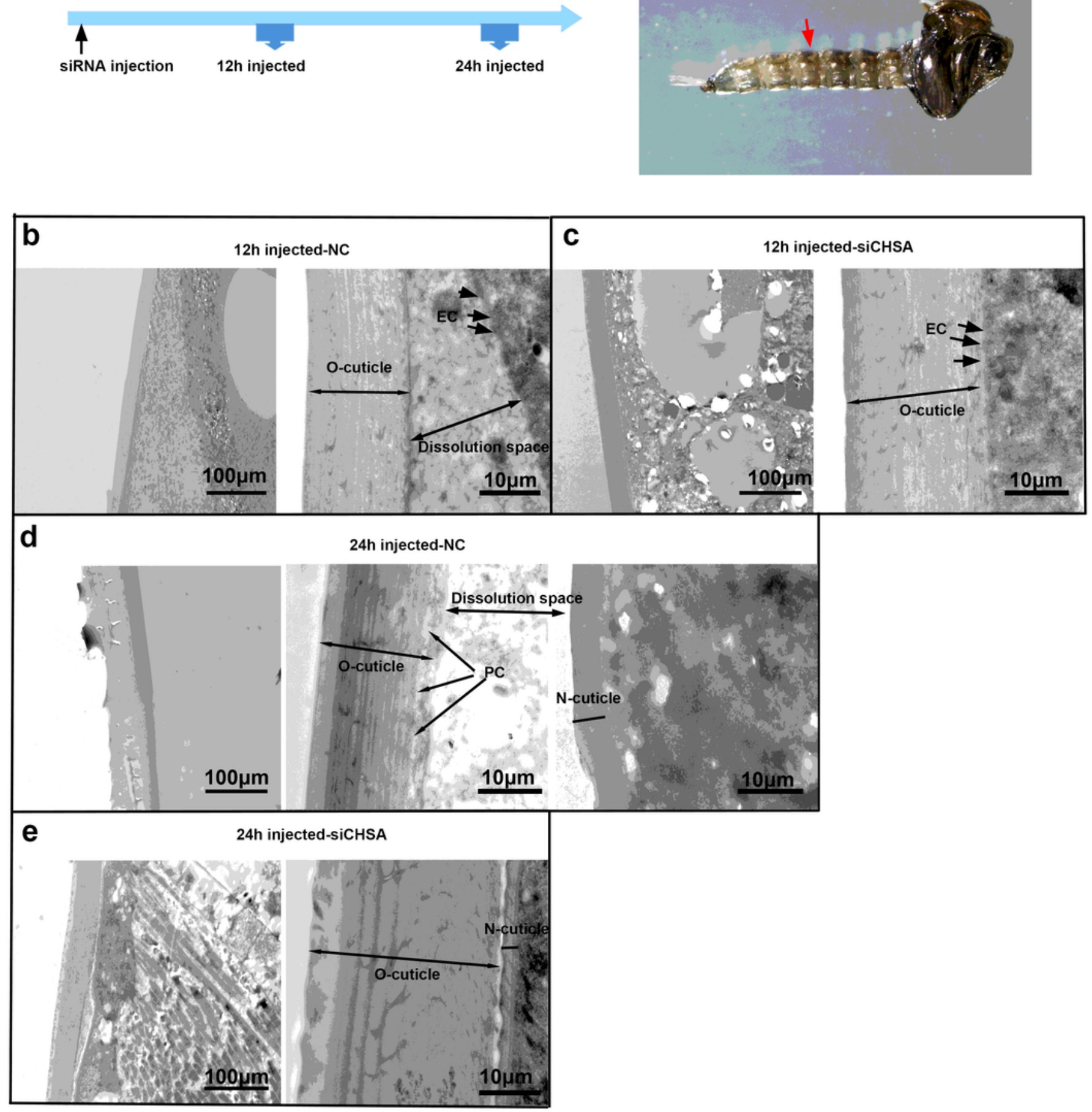

\section{Figure 7}

Ultrastructure of pupal cuticle from CpCHSA-deficient mosquitoes. (a) We analyzed the results using TEM. The pupal abdomen cuticles in the NC (b), and the siCHSA groups (c) at $12 \mathrm{~h}$ after injection. The pupal abdomen cuticles in the NC (d), and the siCHSA groups (e) at $24 \mathrm{~h}$ after injection. 0-cuticle, old cuticle; $\mathrm{N}$ cuticle, new cuticle; PC, pore canal; EC, epithelial cell 

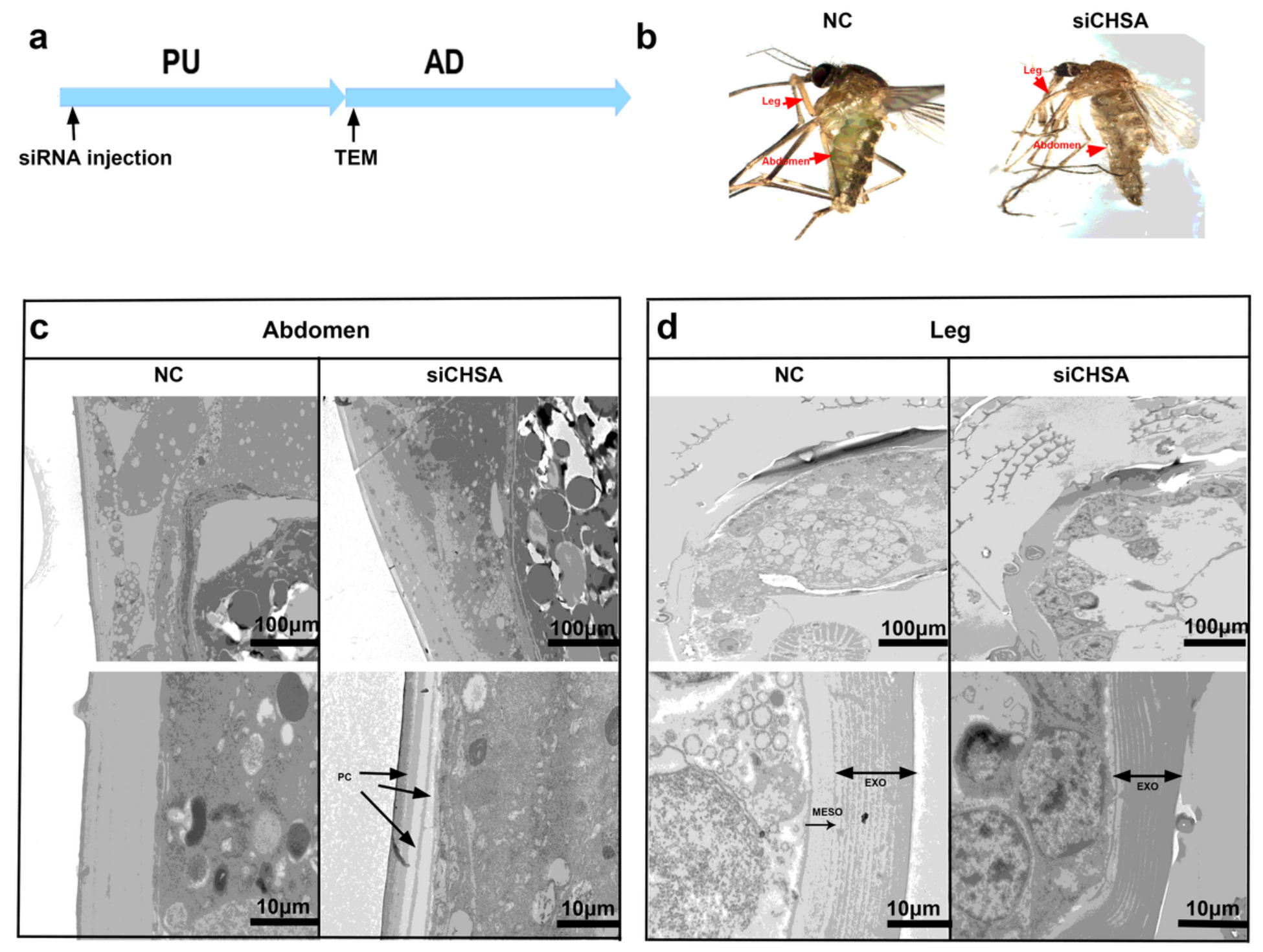

\section{Figure 8}

Ultrastructure of leg and abdominal cuticles from CpCHSA-deficient adults. (a) NC or siCHSA was injected into $0-1 \mathrm{~h}$ pupae (300 ng per pupae). (b) The ultrastructure of $24 \mathrm{~h} \mathrm{PE}$ insects was analyzed using TEM. Insects injected with NC or siCHSA. In the NC and siCHSA groups, (c) there were differences in the thickness and structure of the abdominal cuticle, (d) there were differences in the leg cuticle between the NC and the siCHSA groups. PC, pore canal; EXO, exocuticle; MESO, mesocuticle 
a

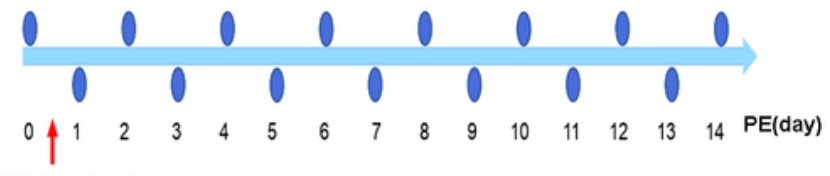
siRNA injection

C

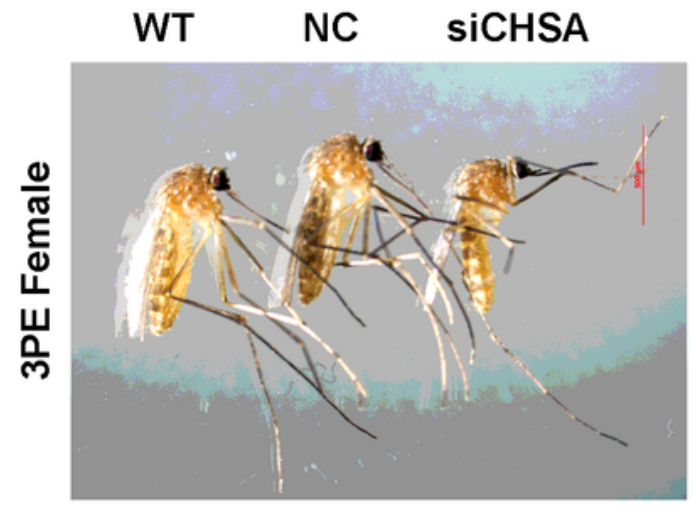

e

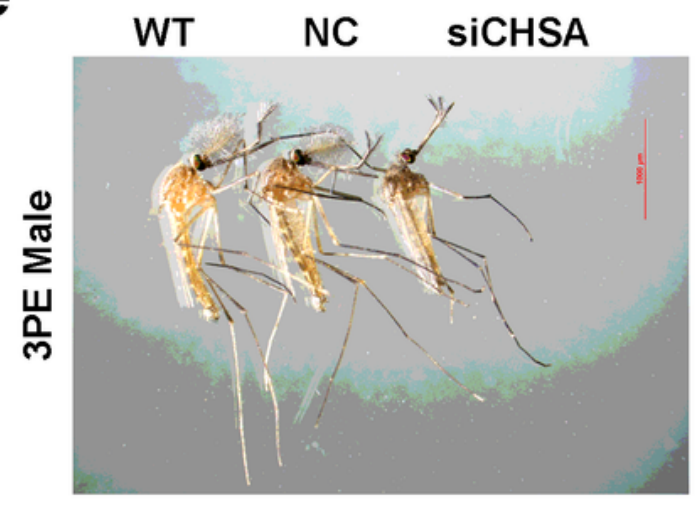

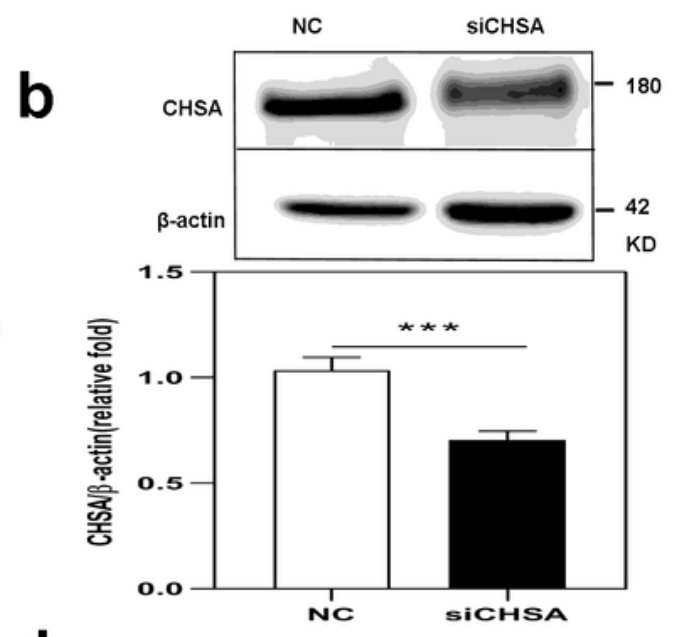

d
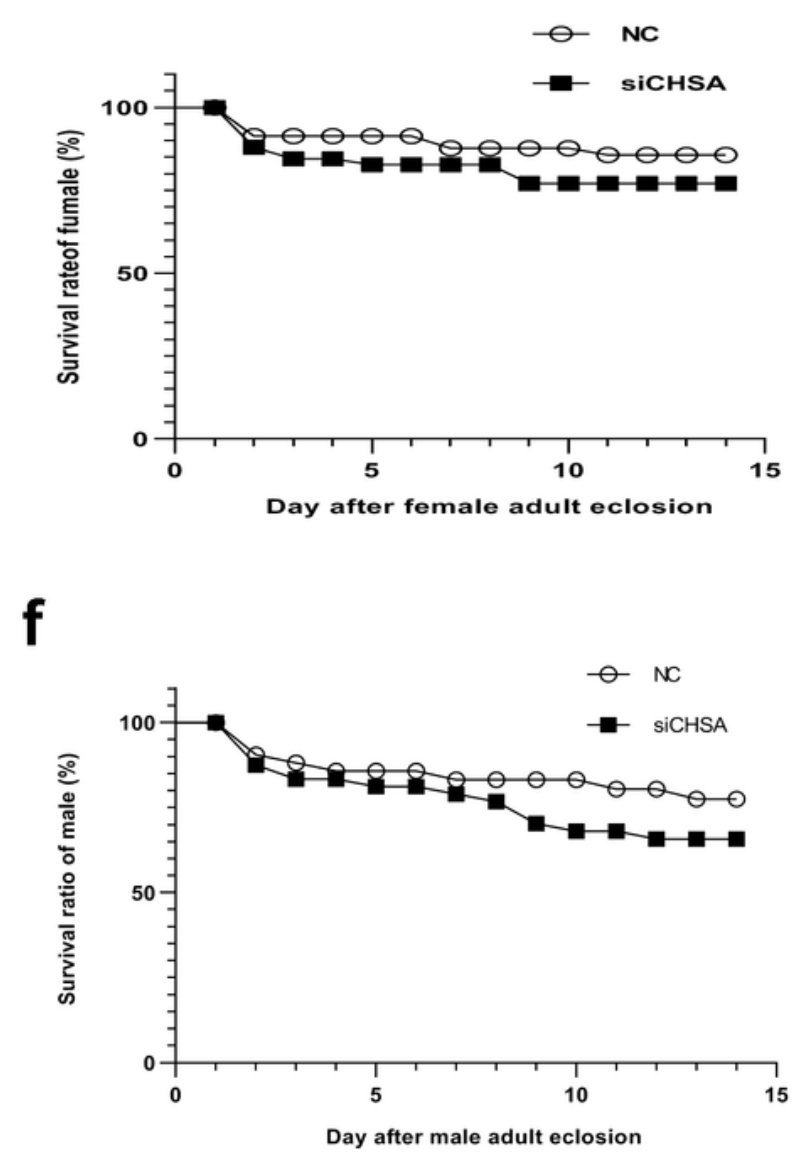

\section{Figure 9}

Phenotypes produced by RNAi of CpCHSA in the adult stage. (a) The 12-24 h PE mosquitoes were injected with siCHSA (300 ng per mosquito) or NC (controls). (b) At the $72 \mathrm{~h}$ PE stage, CpCHSA protein levels were determined using western blotting analysis with a CpCHSA-specific polyclonal antibody. (c) Injection of siCHSA had no effect on the adult phenotype. (d) Injection of siCHSA had no effect on the 
adult survival rate within 14 days. The results are shown as the mean $\pm \operatorname{SEM}\left({ }^{*} \mathrm{p}<0.05,{ }^{\star \star} \mathrm{p}<0.01,{ }^{\star \star *} \mathrm{p}<\right.$ 0.001)

a
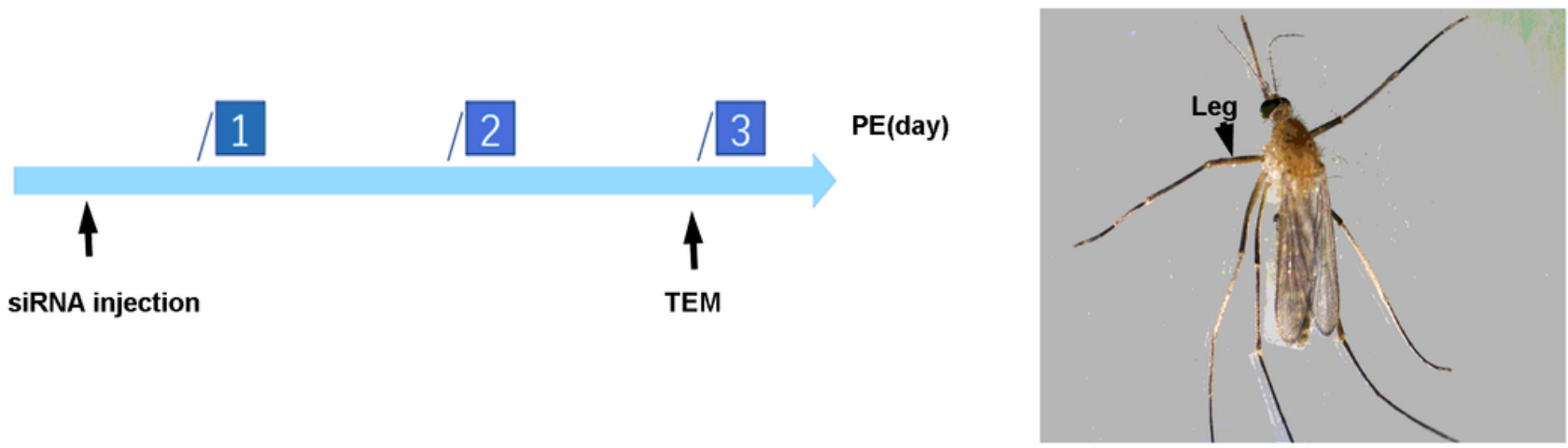

b
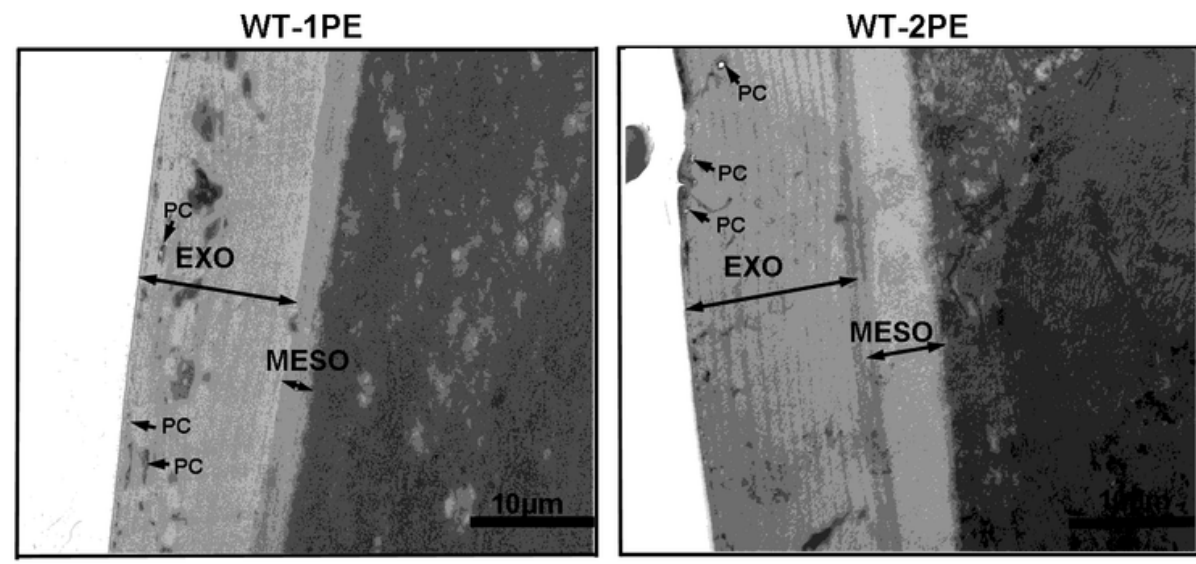

WT-3PE

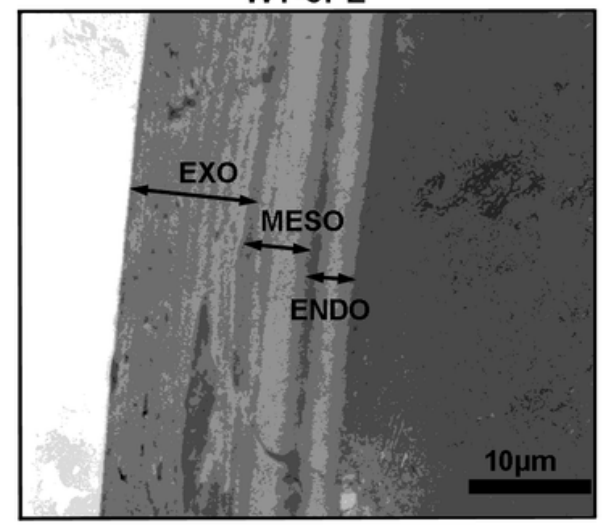

NC-3PE

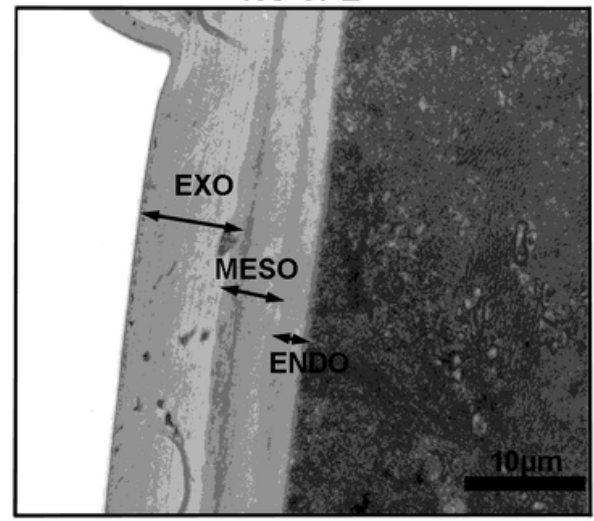

siCHSA-3PE

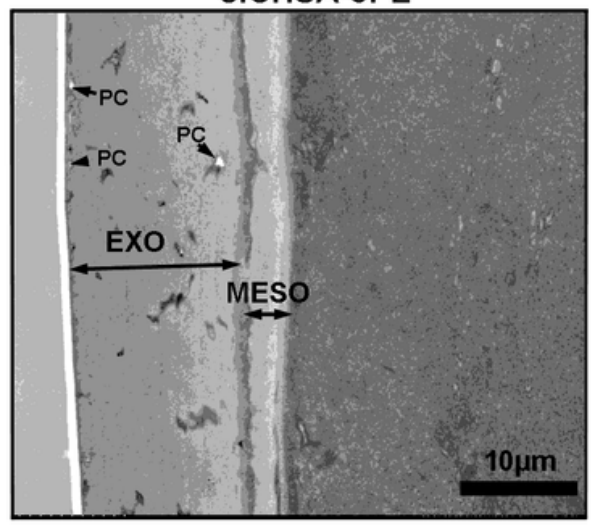

\section{Figure 10}

Analysis of the ultrastructure of mosquito leg cuticles. (a) The 12-24 h PE mosquitoes were injected with siCHSA (300 ng per mosquito) or NC (controls). After $72 \mathrm{~h}$, the PE mosquito legs were collected. (b) Leg cuticles were collected from wild type (WT) PE mosquitoes (at 24, 48, and $72 \mathrm{~h}$ ). (c) Representative transmission electron microscopy (TEM) images from NC, and siCHSA. PE, posteclosion; EXO, exocuticle; ENDO, endocuticle; MESO, mesocuticle 


\section{Supplementary Files}

This is a list of supplementary files associated with this preprint. Click to download.

- SupplementryTables.doc

- GraphicalAbstract.tif 